\title{
Domestic exposure to formaldehyde significantly increases the risk of asthma in young children
}

\author{
K.B. Rumchev*, J.T. Spickett*, M.K. Bulsara\#, M.R. Phillips*, S.M. Stick"
}

\begin{abstract}
Domestic exposure to formaldehyde significantly increases the risk of asthma in young children. K.B. Rumchev, J.T. Spickett, M.K. Bulsara, M.R. Phillips, S.M. Stick.
\end{abstract} (C) ERS Journals Ltd 2002.

ABSTRACT: Concern has arisen in recent years about indoor air pollution as a risk factor for asthma.

Formaldehyde exposure was examined in relation to asthma among young children (between 6 months and 3 yrs old) in a population-based control study carried out in Perth, Western Australia, between 1997-1999. An association between exposure to formaldehyde and asthma in young children has been suggested. Cases $(n=88)$, whose parents were recruited at Princess Margaret Hospital Accident and Emergency Dept (Perth, Western Australia), were children discharged with asthma as the primary diagnosis. Controls $(n=104)$, who were children in the same age group without asthma diagnosed by a doctor, were identified from birth records through the Health Dept of Western Australia (Perth, Western Australia). Health outcomes for the children were studied using a respiratory questionnaire and skin-prick tests. Formaldehyde, average temperature and relative humidity were measured on two occasions, winter (JulySeptember 1998) and summer (December 1998-March 1999) in the child's bedroom and in the living room.

The study found seasonal differences in formaldehyde levels in the children's bedrooms and living rooms with significantly greater formaldehyde exposure during the summer period for case and control subjects. The generalised estimating equation model showed that children exposed to formaldehyde levels of $\geqslant 60 \mu \mathrm{g} \cdot \mathrm{m}^{-3}$ are at increased risk of having asthma.

The results suggest that domestic exposure to formaldehyde increases the risk of childhood asthma.

Eur Respir J 2002; 20: 403-408.
*School of Public Health, Curtin University of Technology, "Department of Public Health, University of Western Australia and "Dept of Respiratory Medicine, Princess Margaret Hospital for Children, Perth, Western Australia.

Correspondence: K. Rumchev, School of Public Health, Curtin University of Technology, GPO Box U1987, Perth, Western Australia.

Fax: 61892662958

E-mail: K.Rumchev@curtin.edu.au

Keywords: Asthma

children

formaldehyde

indoor air quality

Received: May 152001

Accepted after revision: November 30 2001

K.B. Rumchev was the recipient of the Australian Postgraduate Scholarship Award
Asthma is a common chronic childhood disorder in Western countries and there is evidence that it may be increasing in prevalence in all age groups [1]. Although epidemiological studies have given an insight into the risk factors that may be associated with an increased incidence of asthma, the aetiology of asthma remains unclear. While genetic factors are important for determining the risk of asthma, interactions between genetic and environmental factors are likely to explain differences in prevalence between populations and over time. In this context, it is important to establish the environmental factors that influence the development of asthma in predisposed individuals.

Nowadays people spend most of their time $(90 \%)$ indoors [2] and exposure to indoor pollutants has been associated with adverse health effects. Various indoor exposures have been shown to be related to asthma, including house dust mites [3], nitrogen dioxide $\left(\mathrm{NO}_{2}\right)$ [4], and environmental tobacco smoke [5]. A number of studies point to formaldehyde as an important indoor irritant associated with respiratory illness [6]. Formaldehyde is a well-known irritant and according to QuACKENBOSS et al. [7], may induce airway irritation at low concentration. Furthermore, a relationship between attacks of breathlessness and indoor concentrations of formaldehyde has been reported [8]. There is also a study indicating that exposure to formaldehyde emitted from indoor paint is related to asthma [9]. Recently, it has been reported that exposure to formaldehyde in homes might invoke an inflammatory response in the airways of healthy children [10].

This paper presents the association between acute asthma in children and levels of exposure to formaldehyde. The data were collected as part of an indoor environmental study, which also included measurements of indoor $\mathrm{NO}_{2}$, volatile organic compounds, particles with a $50 \%$ cut-off aerodynamic diameter of $10 \mu \mathrm{M}$ (PM10), and allergen levels of house dust mite. The results of these observations will be presented in a separate manuscript.

A population-based case-controlled study was conducted in the Perth Metropolitan area of Western Australia. The hypothesis was that early exposure to higher levels of indoor pollutants, particularly formaldehyde, might predispose young children to asthma. 


\section{Methods}

\section{Study population}

In a population-based case-controlled study children, aged between 6 months and 3 yrs, were studied in order to identify risk factors for asthma that might be important early in life. Cases $(n=88)$ were children who attended the Accident and Emergency Dept at the Princess Margaret Hospital for Children (Perth, Western Australia) and were discharged with asthma as the primary diagnosis. Controls $(n=104)$, who were children of the same age group without asthma diagnosed by a doctor, were identified through the Health Dept of Western Australia (Perth, Western Australia). Controls were recruited from the community rather than the hospital Accident and Emergency Dept because the latter serves as a primary care facility used by families from the whole metropolitan region. Other hospitals within the metropolitan area treat injuries and some more acute medical problems but do not offer a primary care facility. Thus, the cases and controls were both recruited from the same population. A sample from the community is more likely to reflect the demographics of the children with asthma that attend the Accident and Emergency Dept.

\section{Assessment of health symptoms and personal factors}

Information, regarding the respiratory conditions experienced by the study children and characteristics of the home, was collected using a modified, standardised questionnaire of the American Thoracic Society [11]. Parents or guardians of all children were asked to complete the questionnaire and return it to the research team. The questionnaire comprised questions related to potential risk factors for asthma and these factors were grouped in three categories. The first category included information on personal and social factors, such as age and sex of the child, and the mother and father's educational level (elementary school, high school, college, and university). The second category was personal susceptibility factors, which included the child's allergy and respiratory symptoms, parental and sibling's asthma, eczema, and hay fever. Six respiratory symptoms were included: cough, shortness of breath, wheeze, trouble breathing, runny nose and hay fever. The last category comprised environmental exposure in the house, such as parental and visitors smoking inside, exposure to gas heating and cooking, kerosene space heater, fireplace and pets. Other questions related to environmental exposure concerned the presence of air conditioning, a humidifier, recent painting, new furniture and the type of floor covering in the child's bedroom and the living area.

\section{Assessment of atopy}

The atopic status of all study children was assessed by skin-prick tests to the following allergens (Miles Inc., Elkhart, IN, USA) that are most commonly recognised in Western Australian communities: cows' milk, egg white, rye grass, grass mix, Dermatophagoides farinae, D. pteronyssinus (house dust mite), cat, dog, Alternaria spp. and Aspergillus spp. A saline solution was used as a negative control, and histamine as a positive control. The tests were performed between July-September 1998. The largest wheal diameters were measured $15 \mathrm{~min}$ after pricking. The ratio of allergen wheal size divided by the histamine wheal size was calculated. The tests were considered positive if the ratio was $\geqslant 0.5$. Children with at least one positive skin test were defined as atopic following the method by MEINERT et al. [12].

\section{Assessment of indoor exposure}

Measurements of formaldehyde were performed after the emergency visit in winter (July-September 1998) and then during the summer (December 1998March 1999). Controls were monitored during the same period of time as the children who had an emergency treatment for asthma. Passive samples were exposed in the living room and in the child's bedroom for $8 \mathrm{~h}$ during daytime (from 09:00-17:00 h) for each child. In the living room, formaldehyde was monitored in the center of the room, $1.0 \mathrm{~m}$ above the floor, while the bedroom measurements were performed beside the pillow of the bed, at the same height above the floor as the pillow. Indoor concentrations of formaldehyde were measured using passive sampling devices containing glass fibre filters impregnated with 2,4-dinitrophenylhydrazone. The air sampling rate was $77 \mathrm{~mL} \cdot \mathrm{min}^{-1}$. The filters were analysed by liquid chromatography. The method was based on the work reported by LEVIN et al. [13].

Average indoor temperature and relative humidity were recorded with the Tinytalk II Data Loggers (Scientific House, Chichester, West Sussex, UK).

\section{Statistical methods}

Demographic data are expressed as percentages and means (SD). For each season, simple Chi-squared tests and t-tests were performed in addition to univariate and multivariate logistic regression [14], in order to identify important risk factors. Nearly $95 \%$ of cases and $92 \%$ of controls had two observations taken. A generalised estimating equation method [15-17] with an exchangeable correlation structure was used to analyse the data. These models are an extension of multivariate logistic regression analysis and are designed to account for multiple or repeated measures on the same subject. In addition, multiple linear regression models were used to determine any possible house characteristics that might affect the average concentrations of formaldehyde.

The study protocol was approved by the Princess Margaret Hospital Ethics Committee, the Confidentiality of Health Information Committee at the Health Dept of Western Australia and Curtin University Human Research Ethics Committee. Written informed consent 
was obtained from the parents or guardians of all study children.

\section{Results}

\section{Subject characteristics}

Of the study children, $65 \%$ were males and $35 \%$ were females. The mean age of children who had an emergency treatment for asthma was 25 months (7.46 months) and 20 months (7.54 months) for controls. Sixty per cent of all children had at least one positive skin-prick test and were classified as atopic. Significantly (Chi-squared $=10.6, \mathrm{p}=0.001)$ more cases $(72 \%)$ appeared to be atopic, compared with controls (50\%). Sixty-three per cent of cases and $41 \%$ of controls had a parent or sibling with asthma (Chi-squared=10.7, $\mathrm{p}=0.001)$. Forty-five per cent of control subjects had wheeze compared to $85 \%$ in case subjects (Chisquared $=61.98, \mathrm{p}=0.000)$. With regard to other respiratory symptoms, runny nose and cough also appeared to be more common among children who had emergency treatment (83 and $86 \%$, respectively) compared to controls ( 72 and $76 \%$, respectively) (Chi-squared=19.28, $\quad \mathrm{p}=0.000 ; \quad$ Chi-squared $=21.97$, $\mathrm{p}=0.000$, respectively).

\section{Characteristics of living conditions}

The mean indoor formaldehyde levels in the child's bedroom and in the living room, calculated from individual measurements, were $30.2 \mu \mathrm{g} \cdot \mathrm{m}^{-3}$ and $27.5 \mu \mathrm{g} \cdot \mathrm{m}^{-3}$, respectively, with a maximum of $224 \mu \mathrm{g} \cdot \mathrm{m}^{-3}$ and $189.7 \mu \mathrm{g} \cdot \mathrm{m}^{-3}$, respectively. A total of seven indoor samples exceeded the current Australian indoor guideline of $120 \mu \mathrm{g} \cdot \mathrm{m}^{-3}$ [18].

A significantly $(\mathrm{p}<0.01)$ higher proportion of case subjects had a higher formaldehyde exposure $\left(38 \mu \mathrm{g} \cdot \mathrm{m}^{-3}\right)$ compared to controls $\left(24 \mu \mathrm{g} \cdot \mathrm{m}^{-3}\right)$. In addition, there was evidence of seasonal difference in formaldehyde levels in the child's bedroom and in the living room with significantly $(\mathrm{p}<0.01)$ greater formaldehyde exposure during the summer period for case and control subjects (fig. 1 and fig. 2). The study also established a significant positive relationship between formaldehyde levels and indoor temperature $(\mathrm{p}<0.01)$.

Children who reported wheeze were also exposed to higher average indoor levels of formaldehyde $\left(40.5 \mu \mathrm{g} \cdot \mathrm{m}^{-3}\right)$ compared to those without such symptoms $\left(26.7 \mu \mathrm{g} \cdot \mathrm{m}^{-3}\right)$ and the difference was significant $(\mathrm{p}<0.01)$. Children who reported other study symptoms related to asthma, such as runny nose and hayfever, had greater formaldehyde exposure, $32.5 \mu \mathrm{g} \cdot \mathrm{m}^{-3}$ and $32.7 \mu \mathrm{g} \cdot \mathrm{m}^{-3}$, respectively, compared to those who did not report those symptoms, $26.8 \mu \mathrm{g} \cdot \mathrm{m}^{-3}$ and $26.7 \mu \mathrm{g} \cdot \mathrm{m}^{-3}$, respectively, although the difference was not significant.

As part of the questionnaire survey, parents/ guardians were asked to provide information about the smoking status (family members or visitors) in the house. According to the study data, $94 \%$ of controls

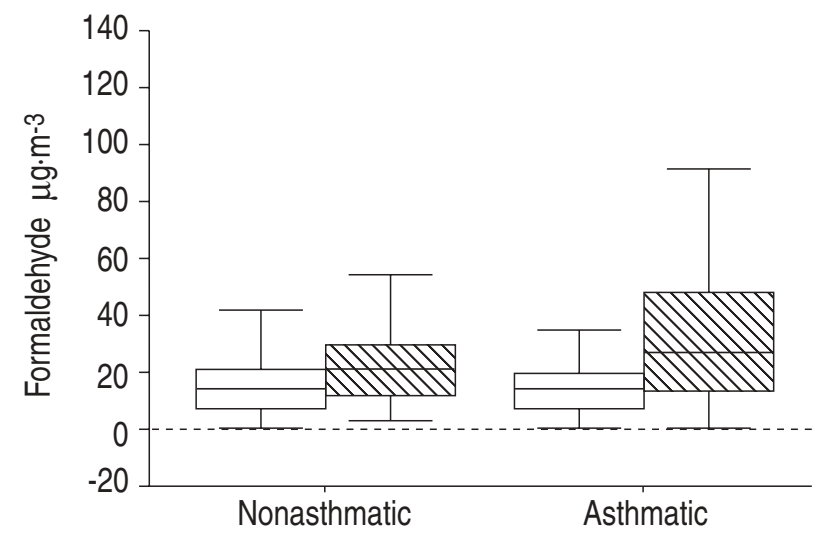

Fig. 1.-Box plots of the seasonal difference in formaldehyde exposure levels in the child's bedroom. Data are presented as means $\pm 95 \%$ confidence intervals. $\square$ : winter; $\mathbb{\mathbb { N }}$ : summer.

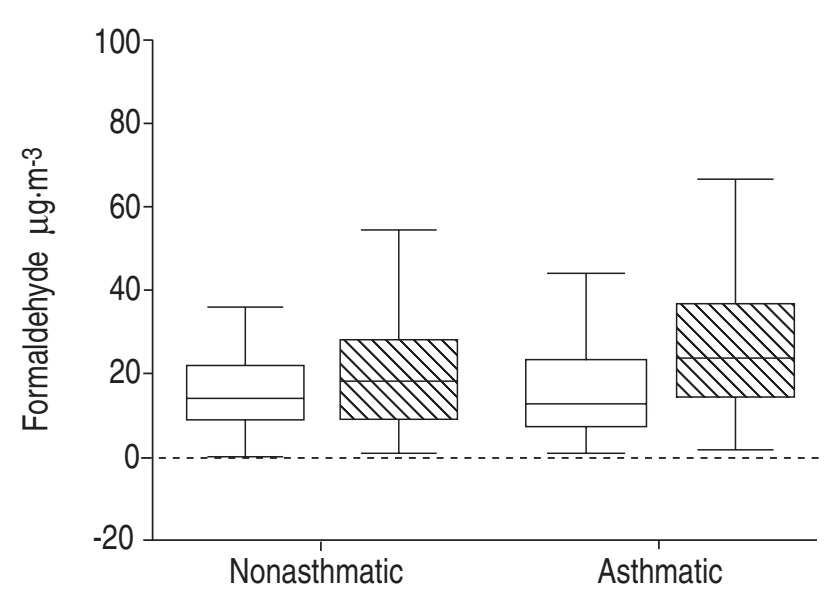

Fig. 2.-Box plots of the seasonal difference in formaldehyde exposure levels in the living room. Data are presented as means $\pm 95 \%$ confidence intervals. $\square$ : winter; $\mathbb{\mathbb { Q }}$ : summer.

reported a smoke-free home environment compared to $80 \%$ of case subjects.

In the present study, the house characteristics that significantly $(\mathrm{p}<0.01)$ contributed to increased indoor levels of formaldehyde were presence of a gas heater (unflued) and a new carpet. Newly-painted surfaces indoors, new furniture and floor boards were also found to be more prevalent among case subjects compared to controls, although the difference was not significant (table 1). A possible explanation for higher formaldehyde levels in some homes is an insufficient air exchange rate and this is consistent with the study finding that significantly $(\mathrm{p}<0.01)$ more control subjects $(52 \%)$ used air conditioning compared to cases $(33 \%)$.

\section{Risk factors for asthma}

According to the generalised estimating equation results, age (odds ratio $(\mathrm{OR})=1.09,95 \%$ confidence interval (CI) 1.05-1.14), child allergies $(\mathrm{OR}=2.57,95 \%$ CI $1.37-4.84)$, and family history of asthma $(\mathrm{OR}=2.66$, 
Table 1.-Prevalence of house characteristics among case and control subjects

\begin{tabular}{lccc}
\hline $\begin{array}{l}\text { House } \\
\text { characteristics }\end{array}$ & $\begin{array}{c}\text { Asthmatics } \\
\%\end{array}$ & $\begin{array}{c}\text { Nonasthmatics } \\
\%\end{array}$ & p-value \\
\hline Gas heater (unflued) & 39 & 35 & 0.6 \\
New carpet & 17 & 9 & 0.12 \\
Newly-painted & & 17 & 0.06 \\
$\quad$ surfaces indoors & 28 & 19 & 0.45 \\
New furniture & 24 & 14 & 0.09 \\
Floor boards & 24 & & \\
\hline
\end{tabular}

95\% CI 1.46-4.88), each adjusted for the other, were independent risk factors for asthma in this study. All ORs have been adjusted for the effect of the measured indoor air pollutants, including allergen levels of house dust mite, relative humidity and indoor temperature. Other known risk factors, such as atopy, family history of asthma, age, sex, socioeconomic status, smoking inside, presence of pets, air conditioning, humidifier and gas appliances, were also included in the model.

Among the indoor environmental factors, higher indoor temperature significantly increased a child's risk of asthma (OR=1.01, 95\% CI 1.00-1.02).

An association between formaldehyde exposure and asthma in children was tested by including formaldehyde levels in the model as a categorical variable, defined with four categories. As can be seen in figure 3, there is a significant increase in risk of asthma associated with exposure to formaldehyde. Children exposed to formaldehyde levels of $60 \mu \mathrm{g} \cdot \mathrm{m}^{-3}$ have a 39\% increase in odds of having asthma compared to children exposed to formaldehyde levels $<10 \mu \mathrm{g} \cdot \mathrm{m}^{-3}$. The formaldehyde results were adjusted for all risk factors mentioned above. The same outcome with regard to formaldehyde is observed if levels of formaldehyde are treated as a continuous variable, as for every 10 -unit $\left(\mu \mathrm{g} \cdot \mathrm{m}^{-3}\right)$ increase in formaldehyde exposure there was an increase of 3\% in the risk of having asthma $(\mathrm{OR}=1.003,95 \% \mathrm{CI}$ $1.002-1.004)$

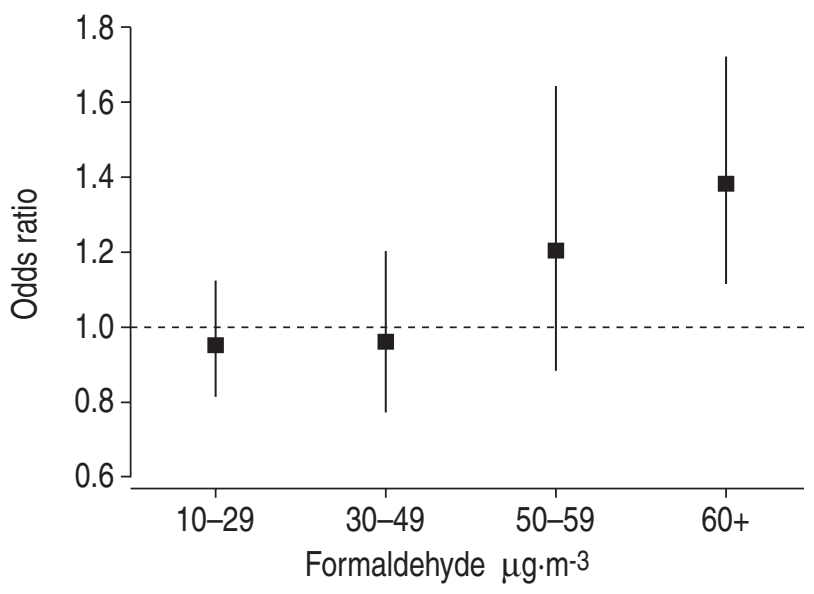

Fig. 3.-Indoor exposure to formaldehyde and risk of asthma. Odds ratio $\pm 95 \%$ confidence interval levels.

\section{Discussion}

Most of the potential risk factors for childhood asthma considered in the present report have been studied previously. Allergies and eczema were considered as expressions of atopy, which is strongly associated with asthma in this study, and consistent with other studies $[19,20]$. A family history of asthma is also a frequently reported risk factor for asthma in other studies [21, 22], which has been confirmed in this study.

As this was a case-controlled study, there were a number of potential sources for bias. The establishment of the case and control groups could be biased if case and control subjects came from different geographical locations. This bias was minimised in this study as both cases and controls were chosen from the Perth Metropolitan area.

As the present study examined the indoor environmental risk factors for asthma, it is more likely that the people who were most interested participated in the study and therefore, a selection bias is expected.

A further source of selection bias in this study may have arisen from refusal of cases or selected controls to participate in the study. Two strategies were employed throughout the data collection phase in order to minimise this possibility. First, to ensure maximum participation by control subjects, the researcher prepared a personal invitation to the child and parents/guardians. Also, encouragement letters from the Health Dept of Western Australia and the Princess Margaret Hospital for Children supported the written invitation. If participation by the respondents was not forthcoming on the first contact, a telephone call was made at a different time of day.

The validity of the diagnosis of asthma in the present study poses a problem, as the study subjects were young and there are difficulties differentiating wheezing illnesses in this age group. Questionnaire responses were also subject to recall or observational biases. Even with the use of a standardised questionnaire of respiratory symptoms, parents may interpret the symptom questions and, therefore, report their child's symptoms in different ways.

Despite the potential limitations, children exposed to levels of formaldehyde of $\geqslant 60 \mu \mathrm{g} \cdot \mathrm{m}^{-3}$ (49 parts per billion (ppb)) are 39\% more likely to have asthma compared to those who are not exposed to such levels. Correspondingly, KRZYZANOWSKI et al. [23] reported that children exposed to formaldehyde levels $\geqslant 60 \mathrm{ppb}\left(74 \mu \mathrm{g} \cdot \mathrm{m}^{-3}\right)$ have significantly greater prevalence rates of asthma and chronic bronchitis compared to those who are exposed to lower levels. In a study by NorbäcK et al. [8], it was suggested that indoor exposure to formaldehyde may cause asthmalike symptoms with a mean formaldehyde concentration of $29 \mu \mathrm{g} \cdot \mathrm{m}^{-3}$ in homes of subjects with nocturnal breathlessness compared with $17 \mu \mathrm{g} \cdot \mathrm{m}^{-3}$ in homes of subjects without nocturnal breathlessness. In a more recent study, exposure to formaldehyde, emitted from recently painted dwellings, was found to be related to asthma [9], with a mean formaldehyde concentration of $24 \mu \mathrm{g} \cdot \mathrm{m}^{-3}$ in painted bedrooms and $32 \mu \mathrm{g} \cdot \mathrm{m}^{3}$ in dwellings with painted walls. These levels are similar 
to those measured in the present study during summer. Other studies [23-25] have also demonstrated associations between exposure to domestic levels of formaldehyde and increased prevalence of asthma and asthma-like symptoms in children.

Formaldehyde concentrations in the study houses were low, with a total of seven samples exceeding $120 \mu \mathrm{g} \cdot \mathrm{m}^{-3}$ (98 ppb), which is the Australian recommended guideline for maximum permissible level within domestic premises and schools [26]. This exposure limit exceeds the Swedish limit for dwellings [8] and the guideline value for formaldehyde determined by the World Health Organization [27], which is $100 \mu \mathrm{g} \cdot \mathrm{m}^{-3}(81 \mathrm{ppb})$. However, only $7 \%$ of children in this study were exposed to levels of formaldehyde $>60 \mu \mathrm{g} \cdot \mathrm{m}^{-3}$ (49 ppb).

According to MARONI et al. [28], the major sources of formaldehyde indoors include gas appliances, open fireplaces, tobacco products, furniture, parquet and other building materials containing formaldehyde. As mentioned earlier, the study results show that important known sources of formaldehyde, such as the presence of a gas heater (unflued), new furniture, newly-painted surfaces indoors etc., were more prevalent among case subjects compared to those in controls, and that a higher proportion of asthmatics had elevated formaldehyde exposure.

One plausible causal link between indoor temperature and asthma in children found in the study implicates functional abnormalities of the airways, resulting from increased exposure to formaldehyde. This can be explained with by significant $(p<0.05)$ relationship between concentrations of formaldehyde and indoor temperature observed in this study. However, other possibilities include the effects of airway warming [29] or dehydration [30].

In conclusion, the present results confirm that some indoor environmental factors contribute as risk factors for asthma in early childhood. Since the quality of the indoor environment is potentially modifiable there might be opportunities for intervention to reduce asthma symptoms. Furthermore, the observation that exposure to formaldehyde very early in childhood is associated with asthma suggests the possibility that irritants in indoor air might be involved in the initiation phase of asthma.

\section{Implications}

Asthma is a considerable health burden in most Western societies and is increasing in prevalence. Although genetic risk factors are important in the development of asthma, it does not explain the tremendous increase in prevalence seen in recent decades. Thus, the indoor environment appears to be of crucial importance since infants spend between $80-90 \%$ of their time indoors at home at a time when immune deviation usually occurs. Over the past $30 \mathrm{yrs}$, the home environment has changed enormously with the introduction of soft furniture, fitted carpets, air-conditioning and central heating. The use of materials emitting formaldehyde is very common and some exposure occurs in every modern home.
Hence, the quality of air inside enclosed spaces where young children spend most of their time has become a matter of growing interest and concern. Young children are considered more susceptible to environmental hazards, so even a small increase in the risk of asthma would lead to large numbers of children being affected.

Indoor guidelines for formaldehyde exposure may need to be reviewed in the light of recent findings.

Acknowledgements. The authors would like to thank the participating households for their valuable contribution to the study.

\section{References}

1. Magnus P, Jaakkola JJK. Secular trends in the occurrence of asthma among children and young adults: critical appraisal of repeated cross sectional surveys. BMJ 1997; 314: 1795-1799.

2. Woodcock A, Custovic A. Avoiding exposure to indoor allergens. BMJ 1998; 316: 1075-1082.

3. Sporik R, Holgate ST, Platts-Mills TEA, Cogswell JJ. Exposure to house dust mite allergen (Der $p 1)$ and the development of asthma in childhood. $N$ Engl $\mathrm{J} \mathrm{Med}$ 1990; 323: 502-507.

4. Hasselblad V, Eddy DM, Kotchmar DJ. Synthesis of environmental evidence: nitrogen dioxide epidemiology studies. J Air Waste Manage Assoc 1992; 42: 662-671.

5. Chilmonczyk BA, Luis MS, Megathein $\mathrm{KN}$, et al. Association between exposure to environmental tobacco smoke and exacerbations of asthma in children. N Engl J Med 1993; 328: 1665-1669.

6. Helwig H. How safe is formaldehyde? Dtsche Med Wochenschr 1977; 102: 1612-1613.

7. Quackenboss JJ, Lebowitz MD, Michaud JP, Bronniman D. Formaldehyde exposure and acute health effects study. Environ Int 1989; 15: 169-179.

8. Norbäck D, Björnsson E, Janson C, Widstrom J, Boman G. Asthmatic symptoms and volatile organic compounds, formaldehyde, and carbon dioxide in dwellings. Occup Environ Med 1995; 52: 388-395.

9. Wieslander G, Norbäck D, Björnsson E, Janson C, Boman G. Asthma and indoor environment: the significance of emission of formaldehyde and volatile organic compounds from newly painted indoor surfaces. Int Arch Occup Environ Health 1997; 69: 115-124.

10. Franklin P, Dingle P, Stick S. Raised exhaled nitric oxide in healthy children is associated with domestic formaldehyde levels. Am Rev Respir Crit Care Med 2000; 161: 1757-1759.

11. Ferris B. Epidemiology standardization project. Am Rev Respir Dis 1978; 188: 1-53.

12. Meinert R, Frischer T, Karamaus W, Kuehr J. Influence of skin prick test criteria on estimation of prevalence and incidence of allergic sensitization in children. Allergy 1994; 49: 526-532.

13. Levin J, Andersson K, Linndahl R, Nilsson C. Determination of sub-parts-per-million levels of formaldehyde in air using active and passive sampling on 2,4-dinitrophenylhydrazine-coated glass fibre and 
high-performance liquid chromatography. Anal Chem 1985; 57: 1032-1035.

14. Hosmer D, Lemeshow S. Applied logistic regression. New York, John Wiley \& Sons, 1989.

15. Liang K, Zeger SL. Longitudinal data analysis using generalized linear models. Biometrika 1986; 73: 13-22.

16. Zeger S, Liang K. Longitudinal data analysis for discrete and continuous outcomes. Biometrics 1986; 42: 121-130.

17. Pendergast J, Gange S, Newton M, Lindstrom M, Fisher M. A survey of methods for analyzing clustered binary response data. Internat Stat Rev 1996; 64: 89118.

18. National Health and Medical Research Council (NHMRC). Interim national indoor air quality goals. The 115th NHMRC session. 1995. Canberra, Australia, Australian Department of Health Aged Care, 1995.

19. Burrows B, Martinez F, Halonen F, Barlee R, Cline M. Association of asthma with serum IgE levels and skin-test reactivity to allergens. $N$ Engl J Med 1989; 320: 271-277.

20. Infante-Rivard C. Childhood asthma and indoor environmental risk factors. Am J Epidemiol 1993; 137: 834-844.

21. Sherman B, Tosteson T, Tager I, Speizer F, Weiss S. Early childhood predictors of asthma. Am J Epidemiol 1990; 132: 83-95.

22. Schenker M, Samet J, Speizer F. Risk factors for childhood respiratory diseases: the effect of host factors and home environmental exposures. Am Rev Respir Dis 1983; 128: 1038-1043.
23. Krzyzanowski M, Quackenboss JJ, Lebowitz M. Chronic respiratory effects of indoor formaldehyde exposure. Env Res 1990; 52: 117-125.

24. Czap C, Nicolai T, Wolf R, Von Mutius E. Asthma, bronchial hyperactivity and formaldehyde exposure in children living near a chip-board factory. Eur Respir $J$ 1993; 6: Suppl. 17, 235s.

25. Garrett M, Hooper M, Hooper B. Low levels of formaldehyde in residential homes and a correlation with asthma and allergy in children. In: Proceedings of the 7th international conference on indoor air quality and climate-indoor air. Japan, Organising Committee of the 7th International Conference of Indoor Air Quality and Climate (Indoor Air'96), 1996; 1: pp. 617622.

26. The National Health and Medical Research Council, Australia (NHMRC). Goals for maximum permissible levels of pollutants in indoor air. Australia, 93rd Session of the National Health and Medical Research Council, 1996.

27. World Health Organisation (WHO). Formaldehyde. Environmental Health Criteria. Geneva, World Health Organization, 1989.

28. Maroni M, Seifert B, Lindvall T. Indoor air quality: air quality monographs, vol. 3. The Netherlands, Elsevier, 1995.

29. McFadden E Jr, Nelson JA, Skowronski M, Lenner $\mathrm{K}$. Thermally induced asthma and airway drying. $\mathrm{Am}$ J Respir Crit Care Med 1999; 160: 221-226.

30. Anderson S, Holzer K. Exercise-induced asthma: is it the right diagnosis in elite athletes? J Allergy Clin Immunol 2000; 106: 419-428. 